\title{
Effects of forming conditions on mechanical properties of resinless bamboo composites
}

\author{
H. Takagi ${ }^{1}$ \& H. Mori ${ }^{2}$ \\ ${ }^{1}$ Department of Mechanical Engineering, \\ The University of Tokushima, Japan \\ ${ }^{2}$ Graduate School of Engineering, \\ The University of Tokushima, Japan
}

\begin{abstract}
This paper deals with the development of resinless, unidirectional bamboo fibre-reinforced eco-composites. Resinless bamboo composites were fabricated by the hot-pressing of unidirectional bamboo fibres extracted by a steam explosion method. The effects of forming conditions on their mechanical properties were investigated. The forming temperature was changed every $20^{\circ} \mathrm{C}$ from room temperature to $180^{\circ} \mathrm{C}$, and the forming pressure used was $10 \mathrm{MPa}$ and $50 \mathrm{MPa}$. Except for the conditions below $60^{\circ} \mathrm{C}$, their tensile strength and fracture elongation decreased with increasing forming temperature. Average tensile strength and Young's modulus of the resinless bamboo composites fabricated at $120^{\circ} \mathrm{C}$ and $50 \mathrm{MPa}$ were $322 \mathrm{MPa}$ and $37 \mathrm{GPa}$ respectively.

Keywords: natural fibre, bamboo, resinless, binderless, unidirectional composites, tensile strength, modulus.
\end{abstract}

\section{Introduction}

Biodegradable composites that are also known as "green" composites are mostly made from natural fibers and a biodegradable resin. Therefore the composites are one of the most environment-friendly materials, because they are finally biodegradable, and thus can be resolved into carbon dioxide and water through the ideal decomposition stage. Hence, many researchers have been conducting the research on biodegradable composites, and especially on their mechanical properties [1-7]. However, most of the biodegradable resins are more expensive than conventional plastics, such as PP and PE. In addition, extra energy is needed 
when the biodegradable resin is made from natural plants, such as corn and potato.

Recently much attention has been paid to the characteristics of engineered wood powder products, which are consolidated under a plastic condition derived from a hot-pressing at high-temperature and high pressure [8-11]. This treatment is called "plasticizing." The wood-plastics made from waste wood powders have also been developed [11], and they have a good prospect of new ecomaterials. However, their strength is low compared with that of conventional engineering plastics. Thus, they need to be strengthened in order to extend their application field.

In recent years, because of a domestic demand of bamboo decreases in Japan, many bamboo forests have been going to ruin. The ruin of bamboo forests causes several environmental problems such as landslides and encroachments against other plants; therefore, much autonomy wants to cut down the bamboo and to utilize them as a raw material of commercial products.

To overcome these problems, in this paper, we have tried to fabricate resinless, unidirectional bamboo fiber composites by hot-pressing of steam-exploded bamboo fibers (abbreviated as bamboo fibers hereafter) without using any adhesives and binders. Particular focus is placed on the effect of hot-pressing conditions on their tensile properties.

\section{Experimental method}

\subsection{Bamboo fibers}

Bamboo fibers were extracted from raw bamboo (phyllostachys pubescens) stem by using a steam explosion method. The condition of the steam explosion was $180^{\circ} \mathrm{C}$ and $40 \mathrm{~min}$. After the steam explosion, bamboo stem became fragile, and long bamboo fibers were easily taken out from the bamboo stem by hand. Soft cells attached on the surface of extracted bamboo fibers were removed by wiping with a wet cloth.

\subsection{Preparation of unidirectional resinless bamboo composites}

First, the bamboo fibers were cut into about $100 \mathrm{~mm}$ in length. Then, the bamboo fibers were set into a metallic mould and finally hot-pressed at various temperatures and pressures for $10 \mathrm{~min}$. The dimensions of specimens are about $10 \mathrm{~mm} \times 100 \mathrm{~mm} \times 1 \mathrm{~mm}$.

\subsection{Tensile tests}

Tensile tests were carried out using an Instron universal test machine (Model 5567). The tensile tests were performed at a crosshead speed of $1.0 \mathrm{~mm} / \mathrm{min}$, with a gage length of $25 \mathrm{~mm}$. Aluminium tabs in $2 \mathrm{~mm}$ thickness were glued at the both ends of the tensile specimen to prevent damages caused by gripping. The shape and dimensions of the tensile specimen are shown in fig. 1. 


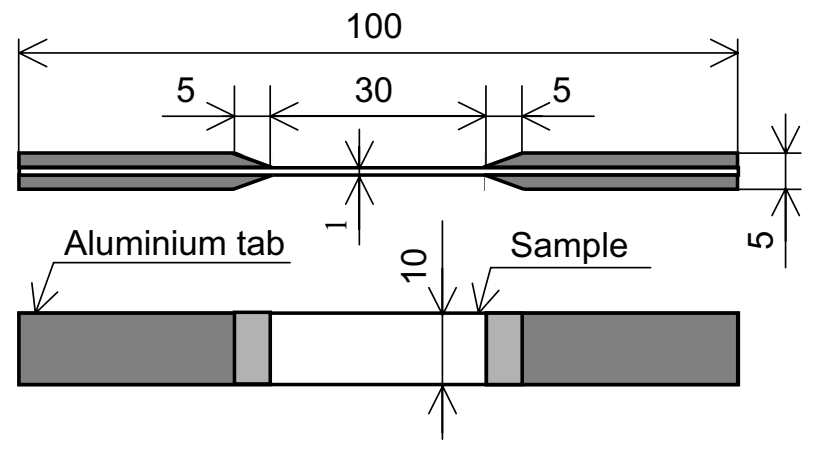

Figure 1: $\quad$ Shape and dimensions of tensile specimens (unit: $\mathrm{mm}$ ).

\section{Results and discussion}

Under the moulding condition of R.T. and $10 \mathrm{MPa}$, bamboo fibres did not adhere to each other; therefore, it was impossible for this sample to carry out the tensile test. However resinless bamboo composites can be fabricated by hot-pressing at temperatures over $80^{\circ} \mathrm{C}$. The colour of surface changed from dark brown to black with increasing the moulding temperature. This colour change might be attributed to the chemical reaction of lignin comprised in bamboo fibres.

Figure 2 shows typical stress-strain curves of resinless bamboo composites moulded at $50 \mathrm{MPa}$ as a function of moulding temperature. The initial slope of the curve (corresponding to Young's modulus) becomes steeper with increasing the moulding temperature, and simultaneously tensile strength also increases. The stress of composites moulded below $180^{\circ} \mathrm{C}$ gradually decrease in the latter part of the deformation. This phenomenon should be responsible for the cumulative fibre fracture. However, the stress-strain curve for the composites moulded at $180^{\circ} \mathrm{C}$ becomes a straight line with the same steep slope as $120^{\circ} \mathrm{C}$. At the same time, fracture behaviour is brittle, and fracture elongation becomes considerably small value less than 0.005 . In the case of moulding pressure of 10 $\mathrm{MPa}$, almost the similar stress-strain curves are obtained as show in fig. 3 .

The relationship between tensile strength of bamboo composites and moulding temperature is shown in fig. 4. The tensile strength reaches a maximum value of about $300 \mathrm{MPa}$ at $120^{\circ} \mathrm{C}$ at both of the moulding pressures. It can be seen from this graph that the bamboo composites become brittle at temperatures over $120^{\circ} \mathrm{C}$, and bamboo fibres do not adhere to each other at temperatures below $120^{\circ} \mathrm{C}$.

The relationship between Young's modulus and moulding temperature is presented in fig. 5. Young's modulus initially increases with the moulding temperature, and then levels off at temperatures above $120^{\circ} \mathrm{C}$. This rise in Young's modulus is consistent with the increase in the density of samples. This is because modulus as well as stress also increases with the moulding temperature.

Figure 6 shows the relationship between fracture elongation and moulding temperature. The fracture elongation is almost constant below $120^{\circ} \mathrm{C}$, and 
decreases with increasing the moulding temperature thereafter. This drop in fracture elongation might be attributed to the increased brittleness of bamboo fibres derived from high temperature exposure [12].

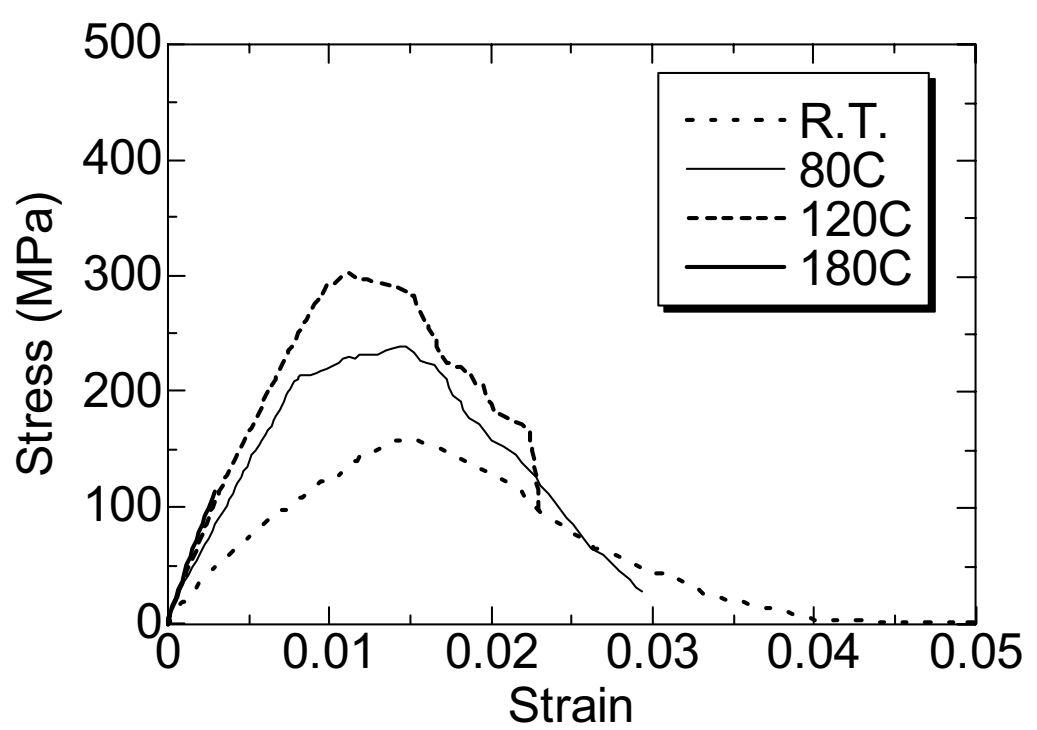

Figure 2: $\quad$ Stress-strain curves of resinless bamboo composites moulded at 50 $\mathrm{MPa}$.

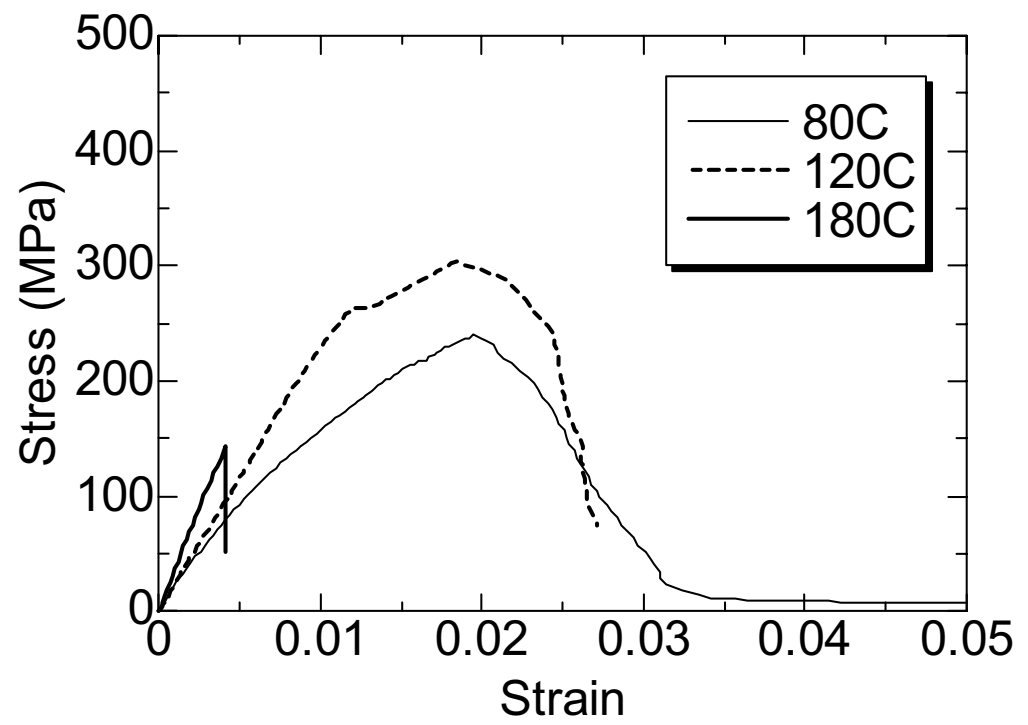

Figure 3: Stress-strain curves of resinless bamboo composites moulded at 10 MPa. 


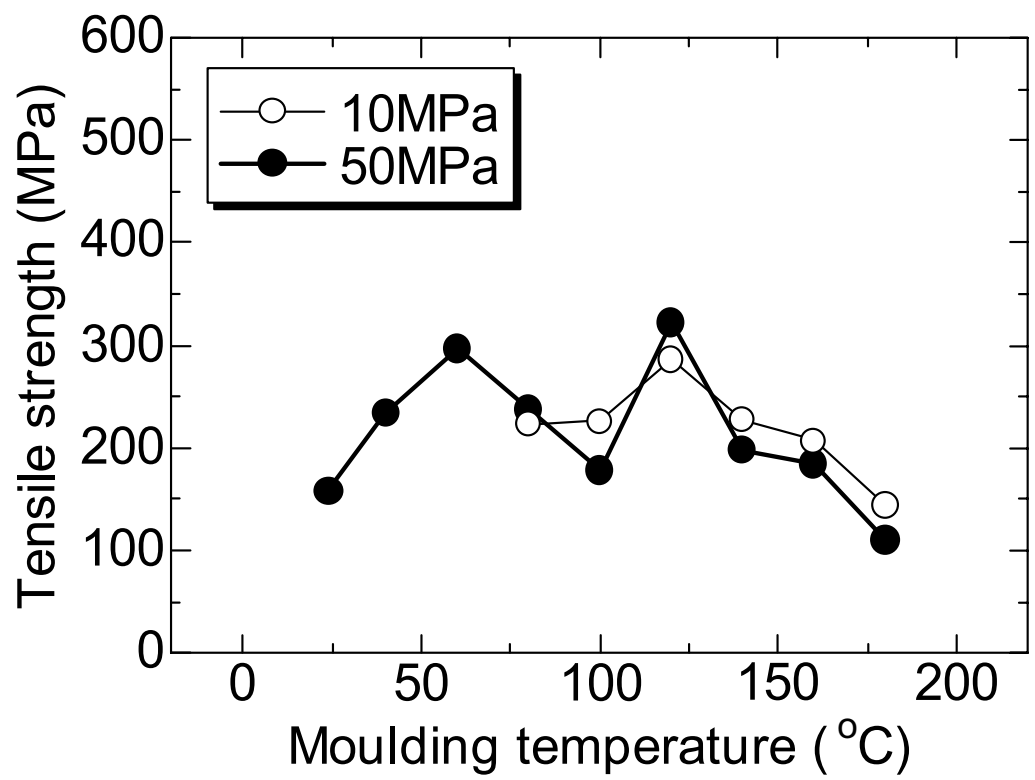

Figure 4: Variation of tensile strength of resinless bamboo composites with moulding temperature.

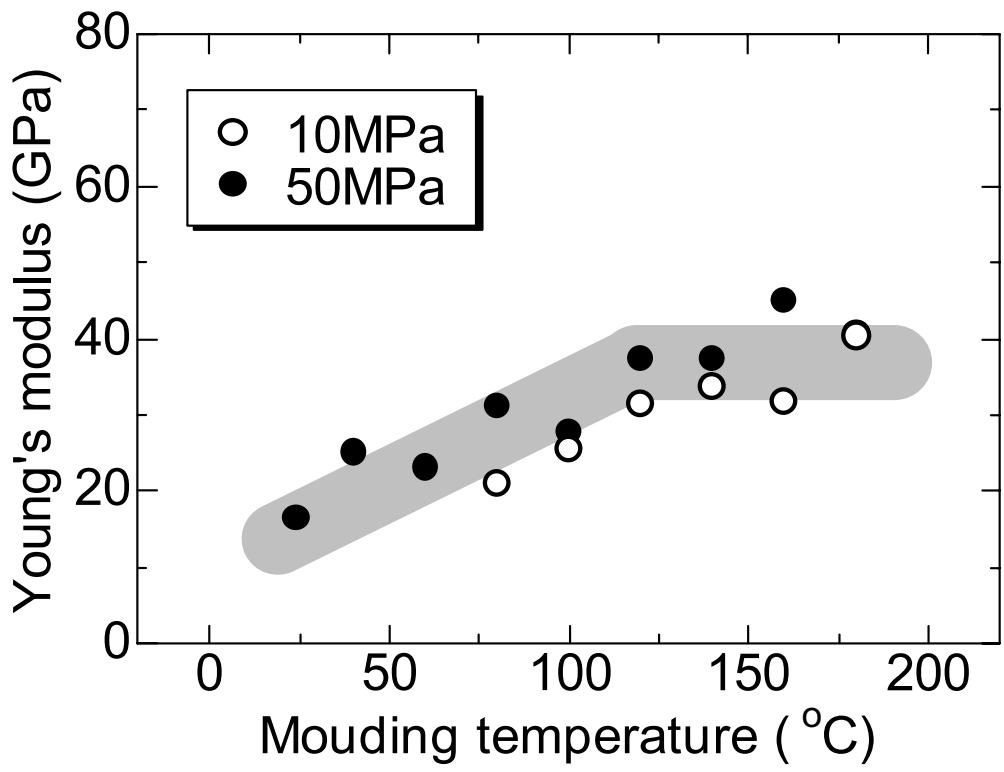

Figure 5: Variation of Young's modulus of resinless bamboo composites with moulding temperature. 


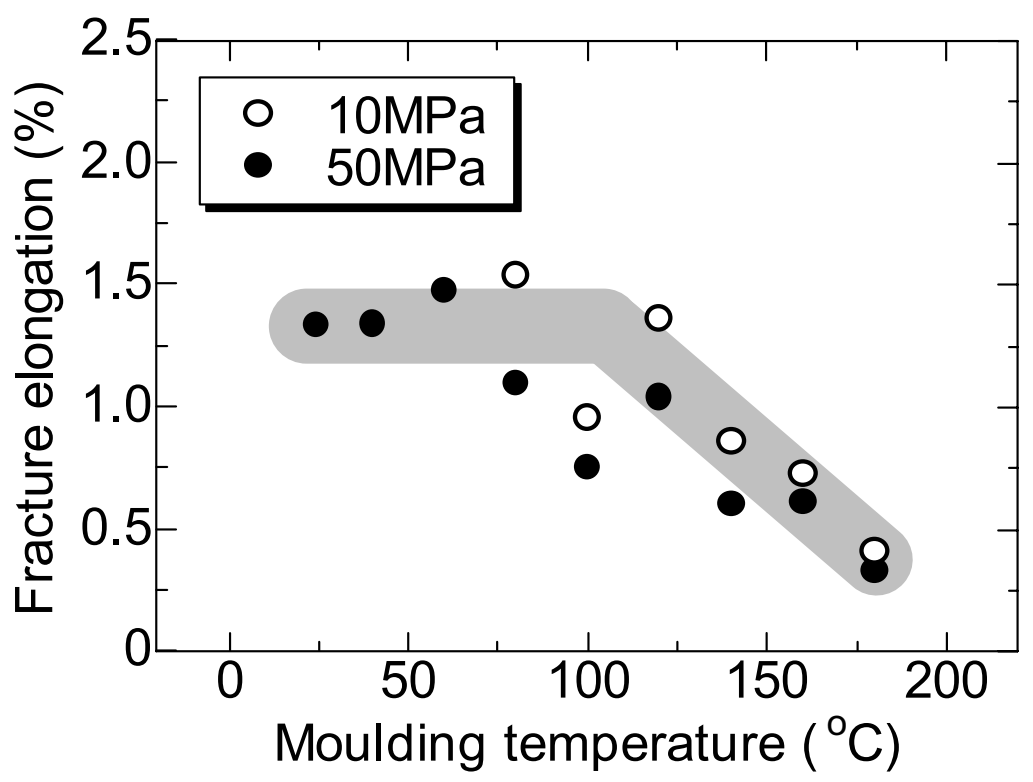

Figure 6: Variation of fracture elongation of resinless bamboo composites with moulding temperature.

\section{Conclusions}

The tensile properties of resinless bamboo composites were investigated. The major results obtained are summarized as follows:

1) Resinless bamboo composites can be made by hot-pressing at temperatures over $80^{\circ} \mathrm{C}$. The optimum moulding temperature is $120^{\circ} \mathrm{C}$ among the conditions investigated.

2) Young's modulus of resinless bamboo composites initially increases with the moulding temperature, and then levels off at temperatures above $120^{\circ} \mathrm{C}$. This rise in Young's modulus is consistent with the increase in the density of samples.

3) The fracture elongation of resinless bamboo composites is almost constant below $120^{\circ} \mathrm{C}$, and decreases with increasing the moulding temperature thereafter. This drop in fracture elongation might be attributed to the increased brittleness of bamboo fibres.

\section{Acknowledgement}

The authors greatly acknowledge the partial financial support provided by the president of The University of Tokushima in 2005. 


\section{References}

[1] Wollerdorfer, M. \& Bader, H., Influence of natural fibres on the mechanical properties of biodegradable polymers, Industrial Crops and Products, 8(2), pp. 105-112, 1998.

[2] Luo, S. \& Netravali, A. N., Interfacial and mechanical properties of environment-friendly "green" composites made from pineapple fibers and poly(hydroxybutyrate-co-valerate) resin, Journal of Materials Science, 34, pp. 3709-3719, 1999.

[3] Mohanty, A. K., Misra, M. \& Hinrichsen, G., Biofibers, biodegradable polymers and biocomposites: An overview, Macromolecular Materials and Engineering, 276/277, pp. 1-24, 2000.

[4] Shibata, M., Takachiyo, K., Yosomiya, R. \& Takeishi, H., Biodegradable polyester composites reinforced with short abaca fiber, Journal Applied Polymer Science, 85(1), pp. 129-138, 2002.

[5] Takagi, H. \& Ochi, S., Characterization of high-strength "green" composites using Manila hemp fibers and starch-based resin, Proceedings of the Third Japan-Canada Joint Conference on New Applications of Advanced Composites (JCJC-III), pp. 19-27, 2003.

[6] Nishino, T., Hirao, K., Kotera, M., Nakamae K. \& H. Inagaki, H., Kenaf reinforced biodegradable composite, Composites Science and Technology, 62, pp. 1281-1286, 2003.

[7] Takagi, H. \& Ichihara, Y., Effect of fiber length on mechanical properties of "green" composites using a starch-based resin and short bamboo fibers, JSME International Journal, Series A, 47(4), pp. 551-555, 2004.

[8] Hillis, W. E. \& Rozsa, A. N., High temperature and chemical effects on wood stability, Wood Science and Technology, 19, pp. 57-66, 1985.

[9] Anglès, M.N., Reguant, J., Montané, D., Ferrando, F., Farriol, X. \& Salvadó, J., Binderless composites from pretreated residual softwood, Journal Applied Polymer Science, 73(12), pp. 2485-2491, 1999.

[10] Salvadó1, J., Velásquez1, J. A. \& Ferrando, F., Binderless fiberboard from steam exploded Miscanthus Sinensis: optimization of pressing and pretreatment conditions, Wood Science and Technology, 37(3-4), pp. 279-286, 2003.

[11] Miki, T., Takakura, N., Iizuka, T., Yamaguchi K. \& Kanayama, K., Production of long rods by sequential extrusion of wood powders, Journal of Materials Processing Technology, 140, pp. 407-412, 2003.

[12] Ochi, S., Takagi, H. \& Niki, R., Mechanical properties of heat-treated natural fibers, Proc. of 1st High Performance Structures and Composites, pp. 117-125, 2002. 